\title{
Promoting Engineering Education Using a State-of-the-Art Research Facility
}

\section{Ms. Grace Altimus, Syracuse University}

Grace Altimus is the operator of the Flow Cytometry and Cell Sorting Core Facility at Syracuse University. She is interested in the improvement of student educational experiences through the use of a shared resource facility.

\section{Prof. Dacheng Ren, Syracuse University}

Dr. Dacheng Ren received his Ph.D. in Chemical Engineering from University of Connecticut in 2003. After finishing postdoctoral training at Cornell University, he joined Syracuse University in 2006. Currently, he is an associate professor in the Department of Biomedical and Chemical Engineering and the Director of Chemical Engineering Graduate Program.

Dr. Ren received an Early Career Translational Research Award in Biomedical Engineering from the Wallace H. Coulter Foundation in 2009 and a NSF CAREER award in 2011. He was named the College Technology Educator of the Year by the Technology Alliance of Central New York in 2010. Dr. Ren is also a recipient of the Faculty Excellence Award from the School of Engineering and Computer Science at Syracuse University. Dr. Ren currently has 44 journal publications with over 2000 citations (h-index 24), 7 issued/pending patents and research supports from NSF, EPA, Wallace H. Coulter Foundation, Alfred P. Sloan Foundation, and industrial sponsors. Dr. Ren has broad research interests in biotechnology and biofilm control. 


\title{
Promoting engineering education using a state-of-the-art research
}

\section{facility}

\author{
Grace A. Altimus ${ }^{1}$ and Dacheng Ren ${ }^{1,2,3,4}$ \\ ${ }^{1}$ Department of Biomedical and Chemical Engineering, Syracuse University, Syracuse, NY \\ 13244 , \\ ${ }^{2}$ Syracuse Biomaterials Institute, Syracuse University, Syracuse, NY 13244, \\ ${ }^{3}$ Department of Civil and Environmental Engineering, Syracuse University, Syracuse, NY \\ 13244 , \\ ${ }^{4}$ Department of Biology, Syracuse University, Syracuse, NY 13244
}

\begin{abstract}
With the mission to solve problems, engineers have created numerous technologies, products, and infrastructures that have transformed our society by improving human life and saving the environment. In this new century, we have entered an even more exciting era with unprecedented opportunities for engineers to keep pushing the limit by finding new sources of renewable energy, seeking cures for previously untreatable diseases, and building systems with extremely high efficiency and accuracy. To meet the demand of modern industries and global competition, it is important to update our curricula and include more advanced topics.
\end{abstract}

To transform engineering education, we developed new course modules and enhanced outreach activities using a state-of-the-art research facility. Specifically, we aimed to create synergy among teaching, research, and outreach using a core facility of flow cytometry funded through 
the MRI program of NSF. A high-end cell sorter and a flow cytometer were used to enhance teaching and outreach.

This facility was used in the junior class of Biological Principles for Engineers. A guest lecture was given by the facility operator to introduce the principles of flow cytometry and cell labeling; and a hands-on lab was designed to use the cell sorter to quantitatively follow bacterial horizontal gene transfer in a model system. These new modules allowed the students to learn cutting edge technologies at first hand and helped them understand not only the knowledge, but also the societal issues related to bacterial antibiotic resistance.

\section{Introduction}

Technology is a moving target; new technology is continuously being developed, while old technology is constantly being applied to new fields and in new ways ${ }^{1}$. A challenge facing engineering education today is to teach students how modern technologies and instrumentation that are commonly used in academic research and industry, making them not just well-rounded college graduates, but also competent and desirable employees ${ }^{[1,2]}$.

Exposure to relevant technologies is most often accomplished through the laboratory portion of applicable courses ${ }^{2}$; yet while many technologies may be easily adopted for use in laboratory demonstration (e.g. DNA purification, gel electrophoresis, etc.), some are too cost-prohibitive to be feasible.

Flow cytometry and cell sorting are powerful technologies that are currently being employed by in both industrial and academic research settings. Both technologies allow single cells to be 
isolated from a population and individually analyzed, revealing characteristics about complex samples at the cellular and sub-cellular levels. Flow cytometry and cell sorting assays can reveal important information describing gene and protein expression, cell cycle, and viability, as well as other characteristics of a cell population ${ }^{3,4}$. Users of these technologies can also distinguish subpopulations within samples and collect them for further study.

These technologies are incredibly important to engineering research; however, both are too expensive to be dedicated to a teaching lab. Using these instruments in a core facility is a good solution. However, the travel to and from the facility presents a challenge to integrate these analyses in a practical teaching lab. To address this issue, a team led by D. Ren applied and received an MRI grant from NSF in order to establish a core research facility of flow cytometry and cell sorting at Syracuse University. The facility is housed in the main engineering building, which is also the home of many classrooms. This setting allows the facility to be accessible with convenience for both research and teaching applications. Thus, this facility provides a unique opportunity to allow students to observe and integrate their use into student laboratories to facilitate not only a greater understanding of the principles of the coursework, but also a command of the technology that translates these principles beyond the classroom. This model was applied to the course Biological Principles for Engineers (BEN 301) and included surveys, a lecture, and a laboratory portion.

\section{Materials and Methods}

Student evaluations. In order to gauge student learning outcomes related to the knowledge of function and operation of flow cytometry and cell sorting instruments, students were given two 
separate evaluations. The first evaluation was a pre-test that was given prior to any lecture or laboratory work involving the technology. This evaluation was intended to establish a baseline of how well students understood the technology. Students were given a follow-up evaluation after attending a lecture discussing flow cytometry technology and performing laboratory exercises. This evaluation was designed to determine how effective the lecture and laboratory exercises were in terms of increasing students' understanding.

Lecture: principles of flow cytometry. A lecture was given by the flow core operator (G. Altimus) which discussed the basic principles of flow cytometry and cell sorting. Topics included basic instrument components (instrument subsystems), flow dynamics, and data generation/ interpretation. A segment of the lecture also covered the particular experiment to be completed by the students in order to explain how cell sorting would be used in this module.

Laboratory exercises. Students participated in a multi-day experiment that reinforced several concepts useful to the field of bioengineering. The laboratory exercise began with overnight cultures of two Escherichia coli strains from glycerol stocks: a donor strain (E. coli CSH26/pKJK10) ${ }^{5}$ containing the pKJK10 plasmid, which expresses green fluorescent protein (GFP), and a recipient strain (E. coli RP437/pRSH103) ${ }^{6}$ containing the plasmid pRSH103, which constitutively expresses the red fluorescent protein dsRed. The E. coli CSH26 strain has the repressor of the $g f p$ gene on its chromosome $e^{5}$ thus, the GFP is only expressed with IPTG induction or when the pKJK10 is transferred to the recipient strain to form a transconjugant. 
Fresh LB medium ${ }^{7}$ supplemented with $30 \mu \mathrm{g} / \mathrm{mL}$ of tetracycline was inoculated with both strains (at a ratio of 3:7, donor:recipient) to an optical density at $600 \mathrm{~nm}\left(\mathrm{OD}_{600}\right)$ of 0.05 . This coculture was mixed and transferred to a filter membrane on an LB agar plates supplemented with 30 $\mu \mathrm{g} / \mathrm{mL}$ of tetracycline, where conjugation was allowed to proceed at $37^{\circ} \mathrm{C}$ overnight. After overnight incubation, membranes were transferred to fresh LB medium supplemented with 30 $\mu \mathrm{g} / \mathrm{mL}$ tetracycline and vortexed to release the cells from the membrane. These samples were then diluted to a concentration of $1.0 \times 10^{6}$ cells $/ \mathrm{mL}$ in phosphate buffered saline (PBS) for cell sorting.

Cell sorting. Conjugation efficiency was examined by cell sorting. Students worked in small groups to sort samples of cells conjugated in previous laboratory periods. Samples contained mixed populations (donor/GFP only, recipient/RFP only, and transconjugant/GFP+dsRED cells) and were examined using a BD FACSAria II cell sorter (Becton Dickinson, San José, CA, USA). Samples were diluted to an optimum concentration of $1.0 \times 10^{6}$ cells $/ \mathrm{mL}$ PBS prior to sorting.

Three populations were sorted for each student group: GFP positive (donor cells), dsRed positive (recipient cells), and double positive (transconjugant cells). Prior to student use of the cell sorter, single and double color controls were used to determine the optimum gating strategy that would allow for efficient sorting of these populations; these standard gates were used for each laboratory group throughout the duration of the course.

Students received a tour of the instrument on-site, observed the sorting process, and received an in-depth explanation of each aspect of the sorting process corresponding to the generation of 
their individual data. Following sorting, each group received an isolated population of GFP only, dsRed only, and transconjugant (dsRed+GFP) cells. Students took the sorted cells back to the lab and plated them on selective media to verify the results.

\section{Results}

Students were given a pre-lecture evaluation prior to attending the flow cytometry lecture, which also preceded the beginning of the relevant laboratory sections. Students were asked a variety of questions that assessed knowledge of concepts related to flow cytometry theory (Table 1).

Student responses were collected and quantified. As shown in Table 1, a total of 36 students participated in the pre-lecture evaluation. All students recognized that not all cells have the same size and/or shape. Similarly, a majority of students (32/36) correctly identified that there is a physical means of separating mixtures of cells. When given a list of potential means of separation (filter paper, gravity, electrical charge, or none of the above), however, responses varied. The students were fairly split with regards to separation by each of the physical methods suggested. This was expected, as the students were not familiar with this topic. This evaluation thus served as a baseline to evaluate the outcome of the teaching model.

Students were also given a post-laboratory evaluation following the final laboratory portion of the exercise. The evaluation contained a variety of questions that sought to determine how much 
knowledge students had retained regarding flow cytometry/cell sorting, as well as opinion questions regarding flow cytometry and engineering research (Table 2).

Due to variation in attendance, more students participated in the post-laboratory evaluation (42 students) than in the pre-lecture evaluation (36 students). Nearly all students (41/42) recognized that flow cytometry is able to distinguish between different cell types (Table 2). Additionally, a majority of students (34/42) recognized that flow cytometry is able to distinguish between cells of the same type (Table 2). Students were asked how flow cytometry might distinguish between cells of the same type; there was no single correct answer, and many students provided one or more reasonable response(s) (Table 2). Students were then asked to describe the type of data that is generated by flow cytometry, choosing from a list of four options rather than generating individual responses (Table 2). The final two questions were used to gather student opinion data regarding the lecture/laboratory experience. Student responses indicate that understanding of research technologies in engineering changed as a result of this experience (Table 2). Students also overwhelmingly expressed the opinion that flow cytometry would be a useful technology in the field of bioengineering research (Table 2).

During the laboratory portion of the exercise, each student group generated a group of plots that included data to describe each of the populations being analyzed. The operator (G. Altimus) helped students to understand the plots that were generated, and how the data related to the samples were provided. A representative sample of student data is provided here (Fig 1). Students generated graphs to examine the donor strain alone (FSC vs GFP fluorescence, Fig 1A) and the recipient strain alone (FSC vs dsRed fluorescence, Fig 1B), as well as a 2-way plot that 
described both GFP and dsRed fluorescence (Fig 1C). This final plot allowed students to observe all subpopulations present in the sample and to observe the strategy used for gating (populations sorted were from gates labelled gfp, dsRed, and both; see Fig 1C).

\section{Discussion}

The pre-lecture evaluation was given to determine the students' background knowledge relating to the principles of flow cytometry and cell sorting. The first two questions were intended to encourage students to think about principles of cell separation ahead of the lecture portion of the exercise. Students successfully identified that cells have different shapes/size based on other topics covered in this class (Table 1), and that it is possible to physically separate a mixture of cells (Table 1). As a follow-up question, students were given a list of potential separation methods and asked to choose which might successfully separate a mixture of cells. Answers were fairly consistently divided between the three methods suggested (filter paper, 19; gravity, 21; electrical charge, 26); however, only one student successfully identified that none of these was a valid method for physically separating a mixture of cells into component populations. This suggests that a disconnection between the general knowledge of cells and of these separation methods exists among the students.

After participating in the lecture and laboratory portions of the exercise, students appeared to have a better grasp of flow cytometry as a technology. The vast majority of students were able to recognize that flow cytometry can distinguish between both cells of different types (41/42 students identified correctly) and cells of the same type (38/42 students identified correctly). As a follow-up question, students were asked to identify what characteristic(s) might allow flow cytometers to distinguish between cells of the same type. Students generated their own answers, 
and the majority of students were able to identify a correct method of separation for cells (30/42 students; Table 2); correct answers included fluorescence (15 students), differential protein expression ( 7 students), and charge assigned by the sorter ( 8 students); incorrect answers included size (4 students), optical density (1 student), and droplet formation (2 students).

Students were also able to correctly identify the types of data generated by flow cytometry from a list of options. There were two correct options on the list: light scatter data (chosen correctly by 36/42 students) and fluorescence data (chosen correctly by 33/42 students). This indicates an improvement from the responses generated during the pre-lecture evaluation, during which a majority of students were unable to correctly identify from a list of methods of physical separation for mixed cell samples. These data together indicate that students were able to form a solid understanding of the principles of flow cytometry; however, it is important to note that a majority of students (30/42) also incorrectly identified optical density as a type of data generated by flow cytometry.

The final two questions were intended to gauge student opinion of the exercise, and responses were overwhelmingly positive. A majority of students (37/42) indicated that the use of the shared resource facility contributed to a better understanding of technology available to engineers engaging in primary research. Similarly, nearly all students surveyed (41/42) indicated that they viewed flow cytometry as a technology that would be useful to engineering research.

Overall, students not only exhibited gains in knowledge related to the technology introduced through the module, but also expressed positive opinions related to their participation in the 
exercises. Both the learning outcomes and the student opinions of the exercise indicate that the use of the shared resource facility in undergraduate coursework results in a positive educational experience.

Integrating advanced technologies in undergraduate education presents an exciting opportunity to better teach knowledge and skills related to these tools. By combining the pre-lecture and postlaboratory evaluations, as well as the lecture and laboratory exercises, a complete learning circle was created which enabled students to understand advanced topics and provided feedback for the instructor to further improve teaching.

\section{Acknowledgements}

The authors are grateful for support provided through NSF MRI grant 1337787 and Syracuse University, which enabled us to establish the core facility on campus and continues to provide support for its operation. Dacheng Ren also received a Faculty Excellence Award from the College of Engineering \& Computer Science at Syracuse, University which has supported the facility in its educational outreach. We also thank the Sorenson lab at the University of Copenhagen for sharing the donor strain, E. coli CSH26/pKJK10.

\section{References}

1. Duderstadt, J. Engineering for a Changing World. The Millennium Project, University of Michigan (2008).

2. Harris, TR, JD Bransford, and SP Brophy. Roles for learning sciences learning technologies in biomedical engineering education: a review of recent advances. Annual Review of Biomedical Engineering. 4: 29-48 (2002). 
3. Davey, HM and DB Kell. Flow cytometry and cell sorting of heterogeneous microbial populations: the importance of single cell analysis. Microbiological Reviews 60: 641-696 (1996).

4. Nebe-von-Caron, G, PJ Stephens, CJ Hewitt, JR Powell, and RA Badley. Analysis of bacterial function by multi-color flow cytometry and single cell sorting. Journal of Microbiological Methods 42: 97-114 (2000).

5. Sorensen, SJ, AH Sorensen, LH Hansen, G Oregaard, and D Veal. Direct detection and quantification of horizontal gene transfer by using flow cytometry and $g f p$ as a reporter gene. Current Microbiology 47: 129133 (2003).

6. Hou, S, H Gu, C Smith, and D Ren. Microtopographic patterns affect Escherichia coli biofilm formation on poly(dimethylsiloxane) surfaces. Langmuir 27: 2686-2691 (2011).

7. Luria, SEBJW. Hybridization between Escherichia coli and Shigella. Journal of Bacteriology 74: 461-476 (1957). 


\section{Tables and Figures}

Table 1: Pre-lecture evaluation questions and student answers

\begin{tabular}{|l|c|c|c|c|}
\hline \multicolumn{1}{|c|}{ Questions } & \multicolumn{4}{c|}{ Student Answers } \\
\cline { 2 - 5 } & Yes & No & $\begin{array}{c}\text { Not } \\
\text { Sure }\end{array}$ & No Answer \\
\hline 1. Are all cells the same size and shape? & 0 & 36 & 0 & 0 \\
\hline 2. Is there any physical way to separate a mixture of cells? & 32 & 0 & 1 & 3 \\
\hline $\begin{array}{l}\text { 3. Could any of these methods be used to separate a mixture of } \\
\text { cells: }\end{array}$ & \multicolumn{3}{|c|}{$\begin{array}{c}\text { A. Filter paper (19). B. Gravity (21). C. } \\
\text { Electrical charge (26). D. None of the } \\
\text { above (1) }\end{array}$} \\
\hline
\end{tabular}


Table 2: Post-laboratory evaluation questions and student answers

\begin{tabular}{|c|c|c|c|c|}
\hline \multirow[b]{2}{*}{ Questions } & \multicolumn{4}{|c|}{ Student Answers } \\
\hline & Yes & No & $\begin{array}{l}\text { Not } \\
\text { Sure }\end{array}$ & No Answer \\
\hline $\begin{array}{l}\text { 1. Would flow cytometry be able to distinguish between } \\
\text { different cell types? }\end{array}$ & 41 & 1 & 0 & 0 \\
\hline $\begin{array}{l}\text { 2. Would flow cytometry be able to distinguish between cells } \\
\text { of the same type? }\end{array}$ & 34 & 8 & 0 & 0 \\
\hline 3. If so, then how might this be accomplished? & \multicolumn{4}{|c|}{$\begin{array}{c}\text { Charge (8) } \\
\text { Fluorescence/lasers (15) } \\
\text { Size (4) } \\
\text { Optical density (1) } \\
\text { Droplets/stream vibration (2) } \\
\text { Gene/protein expression (7) }\end{array}$} \\
\hline 4. What kind of data is generated by flow cytometry? & \multicolumn{4}{|c|}{$\begin{array}{l}\text { Light scatter (36) } \\
\text { Optical Density (30) } \\
\text { Fluorescence (33) }\end{array}$} \\
\hline $\begin{array}{l}\text { 5. Has this lecture/laboratory experience changed your } \\
\text { understanding of the technology currently available/currently } \\
\text { used in research? }\end{array}$ & 37 & 4 & 1 & 0 \\
\hline $\begin{array}{l}\text { Do you think flow cytometry could be a useful technology in } \\
\text { engineering research? }\end{array}$ & 41 & 0 & 0 & 1 \\
\hline
\end{tabular}



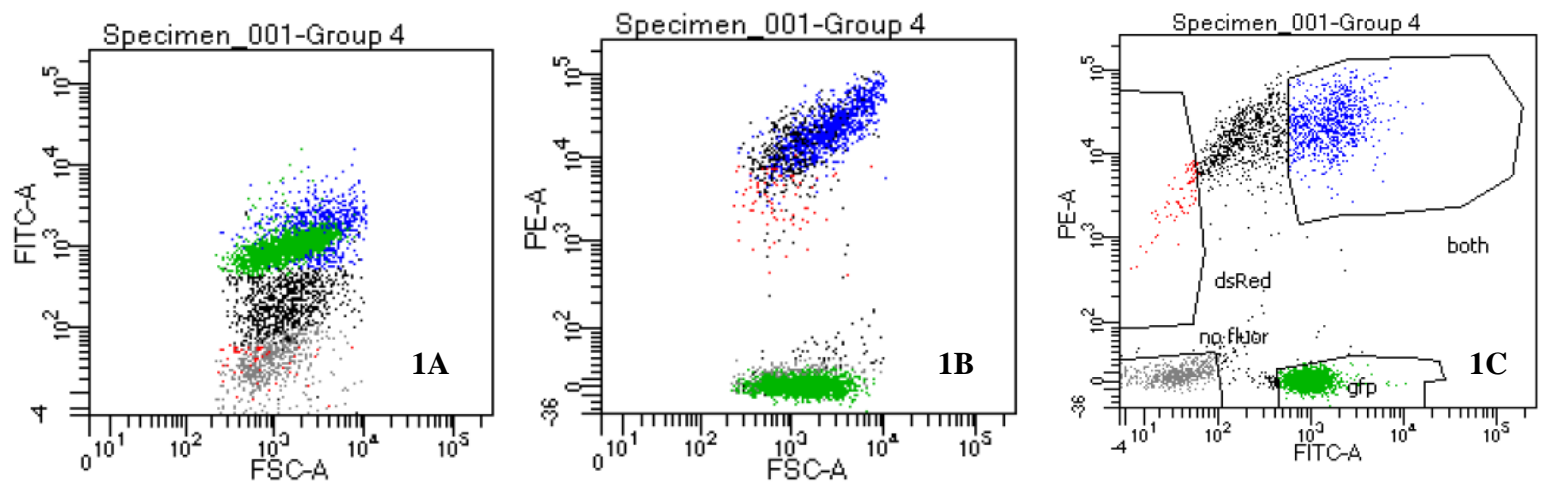

Figure 1: Student cell sorting data 


\section{Figure Legends}

Table 1: Pre-lecture evaluation questions and student answers. The questions contained in the pre-lecture evaluation are reproduced here, along with the student answers collected for each question.

Table 2: Post-laboratory evaluation questions and student answers. The questions contained in the post-laboratory evaluation are reproduced here, along with the student answers collected for each question.

Figure 1: Student cell sorting data. A typical set of graphs generated by a student group during the laboratory portion of the module. Each group generated three relevant fluorescence graphs. A) The subpopulation that is GFP-positive (i.e., the donor only). B) The subpopulation that is dsRed-positive (i.e., the recipient only). C) This plot show GFP fluorescence (x-axis) vs. dsRed fluorescence (y-axis). There are four relevant subpopulations in this plot: no fluorescence, GFP-only (donor), dsRed-only (recipients), and both (have both GFP and dsRed fluorescence; transconjugants). Sorting proceeded using the 'gfp', 'dsRed', and both gates described in this figure. 